\title{
INCLUSÃO ESCOLAR E BARREIRAS ATITUDINAIS: UM DIÁLOGO SOB A PERSPECTIVA DA SOCIOLOGIA DE PIERRE BOURDIEU
}

Prof. Ms. Ernani Nunes Ribeiro

ernaninribeiro@gmail.com

Docente Programa de Pós-Graduação em Mestrado Profissional em Rede Nacional - PROFBIO Ensino de Biologia UFPE/UFMG

Prof. Dr. José Luís Simões

joseluis2711@yahoo.com.br

Docente do PPGE da Universidade Federal de Pernambuco

Prof. Dr. Fábio da Silva Paiva

fabiosilvapaiva@hotmail.com

Docente na Universidade Federal de Pernambuco 
RESUMO: Este artigo objetiva refletir sobre a teoria da inclusão educacional na perspectiva das barreiras atitudinais vivenciadas no espaço escolar. Mais especificamente, com base na leitura de Pierre Bourdieu, se discutirá o modo como referências negativas impactam o direito do acesso aos espaços escolares por pessoas com deficiência. Para tanto, com base numa análise crítica documental, propõe-se uma nova percepção sobre os aspectos sociais que promovem barreiras atitudinais e excluem pessoas cujo perfil difere do padrão populacional. Em outras palavras, o modo como a inaptidão em adequar-se a um corpo discente distante do padrão por parte das instituições educacionais faz com que os jovens com deficiências terminem tidos como inaptos para a educação formal.

PALAVRAS-CHAVE: educação inclusiva, barreiras atitudinais, pessoas com deficiência.

\section{INCLUSIVE EDUCATION AND ATTITUDINAL BARRIERS: ARGUMENTS FROM PIERRE BOURDIEU'S SOCIOLOGY}

ABSTRACT: This paper aims to discuss the inclusive education by attitudinal barriers' perspective. That is, based on Pierre Bourdieu work, it is going to discuss how negatives references impacts the educational access to students with disabilities. To do this, under a critical analysis on the theoretical framework, this paper is proposing a new approach about social aspects that promotes attitudinal barriers and are responsible for the exclusion of non-standardized students. In other words, the goal of this paper is to discuss the inability of scholar institutions in adapt itself to receive students from a different background or with special necessities. In face of it, students with disabilities tend to be treated as unable to receive formal education.

KEYWORDS: inclusive education, attitudinal barriers, students with disabilities. 


\section{Introdução}

Esta investigação tem por objetivo apresentar ponderações acerca dos fundamentos da teoria da inclusão educacional apontados numa reflexão sobre a arbitrariedade da exclusão social apresentada por barreiras atitudinais vivenciadas no espaço escolar. Para tal fim, apresenta uma pesquisa de cunho qualitativo, por considerar que os procedimentos para coleta, tratamento e análise dos dados são construídos pelo próprio objeto a ser pesquisado (BAUER; GASKELL, 2005; CHIZZOTTI, 1997). Além disso, utilizamos de método bibliográfico na busca de referências e informações já elaboradas e publicadas por pesquisadores e teóricos que possibilitem esclarecer, aprofundar e dialogar com reflexões para o entendimento e análise do objeto de estudo neste artigo (ALVES-MAZZOTTI, 1999). No processo reflexivo, fazemos uso de análise crítica, pois buscamos desvelar as interconexões entre os fenômenos, bem como as relações das partes com a totalidade, a historicidade dos fenômenos e as suas contradições.

A história das relações sociais aponta que, na maioria das civilizações, as pessoas buscaram em seus pares a harmonia da igualdade (BURKE, 2001). Esta busca poderia ser notada nos sujeitos que procuravam em seus semelhantes aspectos ideológicos análogos. As religiões, os partidos políticos e os times de futebol são exemplos apresentados no senso comum que corroboram tal perspectiva. Os sujeitos que contrariam o acordo harmônico do modelo ideológico sustentado pelo grupo dominante são geralmente excluídos (BOURDIEU, 2007).

O modelo de igualdade é retratado ao longo dos registros preservados nas memórias da história. Muitos foram os discursos que nomearam, rotularam e negaram aos sujeitos o direito de serem diferentes. Comumente percebemos afirmativas culturais representadas em determinismos sociais que negaram às pessoas negras, homossexuais, com deficiência, índios, judeus e tantos outros o direito à vida, ao bem-estar social, à educação e demais direitos.

Ao analisarmos a história da educação, entendemos que seja factual que no passado a escola se estruturava apenas para poucos escolhidos, oriundos hegemonicamente a partir de classes sociais, de poder econômico ou religioso (HARARI, 2016). Nesse contexto, as pessoas desprovidas de bens capitais, de classes sociais ou econômicas menos abastadas, ou ainda, de origem regional, cultural ou religiosa diversa 
do grupo dominante ficavam excluídas total ou parcialmente do acesso ao processo de ensino-aprendizagem promovido pela educação formal (BOURDIEU, 2011). Juntavamse a esses grupos as pessoas com deficiência, à exceção daquelas ricas, como, por exemplo, os filhos de nobres (RIBEIRO; LIMA, 2010).

Pessoas com deficiência, que não atendem ao padrão estabelecido pela cultura ideológica de normalidade, foram e são sempre vitimadas por preconceitos, estereótipos e barreias atitudinais, recebendo o rótulo de limitados e incapacitados, sendo-lhes proibido o exercício de papéis sociais que lhes são de direito.

A ideologia da normalidade é apresentada em discursos, que corroboram ações e/ou omissões para as pessoas, neste recorte, com deficiência, que sofrem cotidianamente com barreiras atitudinais (posturas afetivas e sociais, que se traduzem em discriminação e preconceito) que, em geral, estão travestidas de generalizações, subestimações, rejeições, praticadas sob o manto do tradicional argumento falacioso: "É melhor para ELE” (LIMA; SILVA, 2009).

São muitas as barreiras atitudinais que estão em ações e posturas que permitem que o preconceito se manifeste em convencionalismos explícitos ou mascarados em pessoas de grupos sociais que não estão dentro de um padrão dominante culturalmente estabelecido (LIMA; SILVA, 2009). Ao pensarmos sobre a temática da inclusão, podemos reconhecer que todos os sujeitos têm características e histórias distintas. Porém, Bourdieu (1930 - 2002) aponta que as desigualdades sociais, culturalmente, acabam se tornando em desigualdades naturais. Passando assim a justificar questões que deveriam ser sucumbidas, por serem socialmente concebidas e transformadas em discursos. Neste contexto, entendemos que os sujeitos com deficiência, na maioria dos casos, assumem uma dupla exclusão, uma vez que, além de muitos pertencerem a classes menos favorecidas de capital monetário, ainda apresentam a deficiência que, somada às barreiras atitudinais, negam o acesso aos bens sociais.

Em virtude das ponderações apontadas, discutiremos neste artigo o entendimento da exclusão social e/ou educacional apresentada em barreiras atitudinais no espaço escolar, e estenderemos nossas reflexões com os fundamentos teóricos debatidos na sociologia de Bourdieu. Discutiremos num primeiro momento a inclusão escolar de pessoas com deficiência - um olhar sobre o pensamento do sociólogo Pierre Bourdieu. 
Em seguida, aprofundaremos nossa reflexão sobre a inclusão escolar - refletindo sobre os impactos das barreiras atitudinais na educação regular.

\section{A inclusão escolar de pessoas com deficiência - um diálogo com a sociologia de Pierre Bourdieu}

O sociólogo Pierre Bourdieu traz um pensamento inquieto e desafiador. Ele percorre nas suas reflexões constructos entre o agente social e a sociedade. Para o pensador, a escola é um espaço de reflexão, pois apresenta representações da sociedade e, assim, amplia temáticas para compreender o ser humano em suas relações sociais.

A escola é uma instituição conservadora e a pedagogia reproduz, agrava segregações e constrói rótulos - na maioria das vezes baseada na inteligência, classes sociais ou até mesmo em "dons". Sendo assim, os que não se enquadram no perfil ideal pregado pela educação são postos de lado, exclusos do que lhes seriam de direito social. Logo, podemos compreender que as ações sociais são concebidas por sistemas de representações que, na maioria das vezes, estão fora do alcance do ator social (NOGUEIRA; NOGUEIRA, 2002).

Uma ideia de ilusão naturalista começa a ser apresentada neste contexto, haja vista que, enquanto o senso comum justifica de forma natural ações pertencentes ao fato social, Bourdieu (2007) passa a denunciar que as naturalizações das ações sociais são respondidas pelo próprio complexo processo de socialização.

Podemos identificar que há uma negação da responsabilidade social perante os fatos, que é socialmente explicável, fora do alcance do natural. Partindo dessa premissa, entendemos que a natureza humana pode ser compreendida como uma ideologia. $\mathrm{O}$ ideal de ser humano tem consigo todo um capital social, cultural, estético e vê na ausência destes elementos uma compreensão de menor humanização. No caso das pessoas com deficiência, essa compreensão perpassa atribuindo-lhes um espaço de seres especiais, excepcionais, portadores entre outros adjetivos, sem reconhecê-los enquanto humanos completos.

Com o entendimento de que há construções ideológicas que socialmente marcam espaços de humanos compreendidos, nesse sistema de ideias, como superiores e outros como inferiores, podemos avançar para a perspectiva de que os atores sociais ocupam posições distintas em espaços sociais. 
O espaço de posição social para Bourdieu (2011) apresenta-se como o conceito de campo, que pode ser compreendido como um conjunto de instituições sociais, indivíduos e discursos que se sustentam mutuamente. A sociedade é composta por inúmeros campos que se sobrepõem. Campo é um universo social com propriedades bem definidas (BOURDIEU, 2007). Esse conceito é usado precisamente para se referir a determinados espaços de posições sociais onde diferentes tipos de bens são produzidos, consumidos e classificados.

Utilizando como exemplo o campo escolar, é possível analisar como professores e estudantes disputam espaços e reconhecimento para si mesmos e para suas atuações. E, como em todo campo, já existe aí uma relação entre dominadores e dominados, em que os agentes dominadores têm a tendência, conscientemente ou não, de adotar estratégias de modo a manter a atual estrutura do campo, bem como os critérios de classificação interna do campo (NOGUEIRA; NOGUEIRA, 2002).

De acordo com Nogueira (2006), para Bourdieu:

\begin{abstract}
A escola não seria uma instância neutra que transmitiria uma forma de conhecimento intrinsecamente superior às outras formas de conhecimento, e que avaliaria os alunos com base em critérios universalistas; mas, ao contrário, ela é concebida como uma instituição a serviço da reprodução e legitimação da dominação exercida pelas classes dominantes (NOGUEIRA, 2006, p. 83).
\end{abstract}

A partir de então, são criados órgãos e instrumentos de classificação das produções sobre educação, hierarquizando o campo de acordo com os conceitos estabelecidos pela parte dominante. Os outros indivíduos, por sua vez, ocuparão os espaços restantes, posições inferiores. Os sujeitos serão classificados e escalados de acordo com as habilidades estratégicas de atuação no campo, neste caso, na educação. Os sujeitos que menos se destacam ficam à margem desta classificação.

A Sociologia da Educação de Bourdieu se notabiliza justamente pela diminuição que promove o peso do fator econômico, comparativamente ao cultural, na explicação das desigualdades sociais. Sendo assim, os sujeitos que não têm capital cultural não conseguem adentrar em determinados espaços sociais. Estes sujeitos são excluídos e vivem à margem da sociedade (BOURDIEU, 1989).

Cada campo carrega consigo valores culturais necessários e exclusivos da classe que o domina. Tais valores são classificados internamente no campo, como padrão para atuação neste espaço social. Os sujeitos dominantes são preparados desde sua infância 
com instrumentos sociais para melhor atuarem no campo e essa somática de elementos se caracteriza em capital, neste caso, cultural. A bagagem familiar tem significativo impacto na definição do destino escolar.

Em outras palavras, o sociólogo considera que certos padrões culturais são considerados superiores a outros, distinguindo-se entre alta e baixa cultura. E que tal distinção, na realidade, é mais uma forma de controlar os "possíveis" candidatos a dominantes no campo, neste sentido, “(...) a classe social não se define somente por uma posição nas relações de produção, mas pelo habitus de classe que está normalmente associado a essa posição" (BOURDIEU, 2011).

Para Bourdieu, existem duas possibilidades de comportamento dos indivíduos em posições inferiores: aceitação e subversão.

As relações sociais, muitas vezes, criam no sujeito que não se adequa ao padrão de normalidade construído nas relações de poder, o entendimento de aceitação de sua condição, produzindo a ideia de inferioridade ou mesmo de incapacidade de equiparação a sujeitos que socialmente estão com as habilidades estratégicas de atuação no campo. Exemplificando esta compreensão, temos o modelo de educação especial que por muitos anos entendia que as pessoas com deficiência deveriam ter a formação escolar em instituições de ensino segregadas, com formação curricular e social distintas da aplicada na educação regular.

A justificativa dava-se pelo entendimento da classe dominante que sujeitos que apresentassem qualquer deficiência não teriam condições de acompanhar a formação escolar regular. As aulas eram com enfoque na deficiência e não atendia às necessidades dos educandos de serem inclusos na sociedade, ficando à margem de espaços sociais, que não os acolhiam (MANTOAN, 2003). Muitos sujeitos com deficiência eram aposentados e estigmatizados como inválidos. Em troca da aposentadoria, havia a aceitação da condição culturalmente construída.

A outra possibilidade, a subversão do sistema dominante, nem sempre é possível. Vejamos o exemplo da educação inclusiva que se tem configurado, historicamente, como objeto de luta e defesa da diversidade humana, desde a revolução francesa, com os ideais de liberdade, igualdade e fraternidade. Em 1948, com a declaração dos direitos humanos, o movimento inclusivista ganhou mais força com a sistemática legal em prol da ideologia 
de respeito às diferenças. Porém, este movimento social tem em suas fragilidades a inserção de sujeitos fora do padrão estabelecido pelas classes dominantes em espaços não pensados, projetados e adequados à diversidade. A educação tem sofrido significativos impactos com a inclusão escolar.

Uma vez que sujeitos com deficiência chegam cada vez mais às escolas regulares, o modelo até então projetado para alunos sem deficiência tem apresentado fragilidades (MANTOAN, 2003). Embora seja um movimento subversivo, pois rompe com o ideal de normalidade e segregação, a educação inclusiva sofre constantes ataques alegando que a educação não está preparada para tal perspectiva e deixa ainda mais marcada a relação dominante e dominado, pois pela falta de acessibilidade os sujeitos com deficiência são excluídos no próprio modelo que, falaciosamente, é divulgado pelas políticas públicas educacionais como inclusão.

Ao fazermos um recorte sobre a reflexão anteriormente apresentada, chamamos a atenção para o educando surdo na escola regular. Existe uma significativa barreira comunicacional entre os falantes da língua portuguesa e os da língua brasileira de sinais (LIBRAS), falada em alguns casos como a única língua de comunicação social de pessoas surdas (PERLIN; STROBEL, 2006). Escolas regulares que apresentam alunos surdos em seu quadro discente, muitas vezes, não estão preocupadas em atendê-los ou apresentar as devidas adaptabilidades pedagógicas. $\mathrm{O}$ espaço escolar acaba sendo reflexo da difusão e manutenção de preconceitos apresentados como barreiras, muitas delas nas atitudes, com argumento falacioso: "É melhor para a pessoa com deficiência que estude com seus pares".

Podemos compreender esse fator pelas falas que se caracterizam como discriminatórias, que social e culturalmente são percebidas nos discursos que, muitas vezes, não são ditos, mas expressos em preconceitos, estereótipos e barreiras atitudinais sobre a competência de determinados grupos sociais não apresentarem o perfil do grupo dominante.

Vemos nesse contexto como o discurso de normalidade, dos sujeitos que vivem e dominam os hábitos do campo estudado, legitimando a negação da singularidade do sujeito, justificando, neste contexto, a exclusão. Em outras palavras, para Bourdieu (2011), as decisões e percepções do mundo estariam previamente condicionadas à posição 
social, bem como relacionadas ao grupo social ao qual o sujeito é pertencente. Neste caso, pessoa com e sem deficiência.

Outrossim, os alunos que não atendem ao capital cultural esperado tornam-se "invisíveis" em salas de aula no ensino regular. Exemplificando isso, vemos alunos surdos que, muitas vezes, por não "falarem" língua oral, são "silenciados" mesmo estando postos na frente do docente (LAPLANE; DOBRANSZKY, 2002). Essas reflexões são percebidas nas falas de professores que mantêm o discurso de segregação, não se importando em qualificar suas práticas para atender ao sujeito com deficiência. Ao se arrazoar sobre a formação escolar de educandos surdos, percebemos que esses apresentam lacunas no uso da língua portuguesa. Em particular, esses alunos, por terem a língua visoespacial como língua natural e a língua portuguesa como segunda língua, mostram déficits na instrumentalização da leitura e escrita de línguas orais (QUADROS, 2007).

As barreiras atitudinais alimentam preconceitos e ideologias que não possibilitam reconhecer e acreditar no potencial de alunos com deficiência, levando assim à falta de reflexões e metodologias que proporcionem recursos didáticos eficientes para o processo educacional de alunos com características particulares de aprendizagem.

Mas, como as barreiras atitudinais corroboram o processo de exclusão de sujeitos em escolas regulares?

\section{Inclusão escolar - refletindo sobre os impactos das barreiras atitudinais sofridas por alunos inclusos na educação regular}

As barreiras atitudinais compreendem posturas afetivas e sociais, traduzindo-se em discriminação e preconceito.

Por atitude podemos ampliar nosso entendimento como:

(...) Termo amplamente empregado hoje em dia em filosofia, sociologia e psicologia para indicar, em geral, a orientação seletiva e ativa do homem em face de uma situação ou de um problema qualquer. Dewey considera essa palavra um sinônimo de hábito (v.) e de disposição (v.); em particular, parecelhe que ela designa "um caso especial de predisposição, a disposição que espera prorromper através de uma porta aberta" (Human Nature and Conduct, 1922, p. 41). 
Uma vez que as atitudes podem ser entendidas como uma orientação seletiva e ativa do humano em face de uma situação, criando assim hábitos que predispõem ações, as atitudes dos sujeitos podem ser favoráveis ou negativas frente a uma ação.

As atitudes negativas relacionadas a ações entre sujeitos podem ser caracterizadas de diversas formas. Muitas ações podem ser percebidas em discursos de generalizações e estereótipos relacionados a particularidades em pessoas que não são pertencentes ao grupo dominante. Estas ações promovem preconceitos e exclusões. Estes são os elementos norteadores das barreiras atitudinais. A discriminação pode ser entendida, neste contexto, como habitus culturalmente concebido, gerador de sujeitos com atitudes preconceituosas com atores sociais não pertencentes ao mesmo campo social. Os hábitos discriminadores concebem atitudes limitantes para o diferente, tal qual uma barreira que demarca o espaço social de cada ator.

Segundo Lima e Tavares,

\begin{abstract}
As barreiras atitudinais são barreiras sociais geradas, mantidas, fortalecidas por meio de ações, omissões e linguagem produzidas ao longo da história humana, num processo tridimensional o qual envolve cognições, afetos e ações contra a pessoa com deficiência ou quaisquer grupos em situação de vulnerabilidade, resultando no desrespeito ou impedimento aos direitos dessas pessoas, limitando-as ou incapacitando-as para o exercício de direitos e deveres sociais: são abstratas para quem as produz e concretas para quem sofre seus efeitos. (LIMA; TAVARES, 2012 p.12).
\end{abstract}

Os atores sociais carregam consigo elementos históricos que trazem opiniões e vivências coletivas que repercutem na construção cultural, social e política dos sujeitos. Entendemos que, ao se pensar no movimento de inclusão educacional, deve-se considerar que sujeitos com deficiência foram negligenciados, esquecidos e tiveram os direitos sociais negados.

Enquanto sujeitos humanos, pessoas com deficiência coexistem com as constantes concepções sociais enfocadas nas deficiências, compreendendo-as como limitações e não como humanos que socialmente foram construídos e limitados pela falta de acesso à própria sociedade. 
Mantoan (2006) amplia a discussão comentando que:

\begin{abstract}
As barreiras atitudinais às diferenças raciais, culturais, de gênero, religiosas, familiares, de origem social, a certos talentos e habilidades, a aspectos ligados ao físico e demais estereótipos podem ser removidas, gradualmente, na medida em que enfocamos cada situação preconceituosa e/ou discriminatória com o cuidado necessário, sem banalizar os sentimentos e trivializar os costumes. (MANTOAN, 2006. p.65)
\end{abstract}

Os problemas referentes à inclusão social não se finalizam apenas em inserir alunos com deficiência em escolas regulares. Os indivíduos e as instituições que representam as formas dominantes de cultura e as estruturantes da educação regular buscam manter sua posição privilegiada, naturalizando seus bens culturais. O modelo, tal qual se apresenta na atualidade, obriga aqueles que não são pertencentes à classe dominante a se adequarem à cultura de elite via adaptação de seus bens culturais. Os sujeitos que não se adequam são marginalizados. No caso de sujeitos com deficiência que são inseridos em escolas regulares, ocorre que, muitas vezes, não conseguem adaptar-se e passam a sofrer barreiras atitudinais.

A arbitrariedade cultural ou imposição de cultura é classificada por Bourdieu (1989) como "violência simbólica". A consolidação da violência simbólica permite que a escola reproduza relações de dominação, ou seja, a estrutura de classes. Reproduzida de maneira diferenciada, a ideologia da classe dominante exerce a violência mediante forças simbólicas. Força as pessoas a pensarem e a agirem de tal forma que não percebem que acabam por legitimar a ordem vigente, seja pela doutrinação, seja pela dominação.

$A$ "violência simbólica" materializada em barreiras atitudinais gera consequências que ferem a dignidade, a integridade, a capacidade de ser cidadão, a condição humana nos âmbitos social, político, cultural e moral. Além disso, a autoestima sofre alterações, pois o sujeito pode interiorizar os aspectos negativos e assim se fechar ao resto do mundo. O processo educativo para pessoas com deficiências é uma ação coercitiva, definindo a ação pedagógica como um ato de violência, de força.

Em outras palavras, "violência simbólica" materializada em barreiras atitudinais pode ser percebida em discursos que rotulam alunos como inferiores. Professores que atuam em salas regulares de ensino, ao perceberem que educandos têm um tempo de aprendizagem diferente dos demais da sala, categorizam estes alunos como problemáticos. Esses alunos são, em muitos casos, sujeitos com problemas na visão e ainda sem o diagnóstico, ou alunos com baixa visão, com deficiência intelectual, cegos, 
surdos, obesos, depressivos, de baixo capital cultural, econômico, tantas outras possíveis características. Esses sujeitos são reais e não são contemplados, em suas particularidades, no processo didático. São ignorados em planejamentos, aulas e tarefas escolares, haja vista que o modelo educacional é projetado para um padrão dominante de sujeitos que atende aos princípios de normalidade culturalmente construídos para o campo educacional.

Estigmatizados como "maus alunos", muitos sujeitos com deficiência sofrem por ideologias educacionais normalistas que expõem que eles não aprenderiam, são mais lentos na aprendizagem ou mesmo a deficiência atrapalha a aprendizagem. Essas crianças surdas, cegas, obesas, etc., durante anos, carregaram o peso dos estigmas de "incapacitados", "deficientes" e "especiais" (GOFFMAN, 2004). O senso comum, na maioria dos casos, percebe os sujeitos com deficiência a partir da deficiência em si e não como seres humanos.

As barreiras atitudinais podem ser classificadas em cerca de 20 formas (TAVARES, 2012). Para Tavares (2012), essas barreiras estão enraizadas e competem com barreiras arquitetônicas que também excluem pessoas com deficiência, neste caso, pela deficiência física. Por isso, sabemos que tais barreiras devem ser identificadas nas relações sociais em prol da possibilidade da inclusão social.

Destacaremos três barreiras e as conceituaremos a fim de entender fatores que caracterizam sua essência para, assim, percebê-las em relações sociais no campo educacional. É indispensável ressaltar que separar as barreiras por conta da taxonomia não as desvincula. É um modo de tentar entender melhor esse universo. Como discutimos, barreiras atitudinais se traduzem em discriminação e preconceito.

\section{a) Barreira atitudinal de substantivação}

Segundo Tavares (2012), a barreira atitudinal de substantivação é materializada no discurso quando ele se refere à falta de uma parte ou sentido da pessoa como se a parte "faltante" fosse o todo. A pessoa deixa de ser o humano, sujeito de diversos elementos que o caracterizam como tal e passa a ser a deficiência como elemento totalizante de sua identidade social. Vemos exemplos, como: o deficiente mental, o cego, o perneta, entre outros do senso comum. 
Por séculos, crianças foram condenadas ao isolamento por apresentarem características diferentes do padrão normativo pregado pela cultura dominante. Foi-lhes tirado o direito de serem humanos, de sentirem afeto e de sentirem-se iguais aos seus semelhantes. Educadores os viam como "coisas" ou "defeitos".

Ser inclusivo é romper com isso. É abolir isso, é lutar por exterminar essa “ideologia". É ver na criança com deficiência a criança e não o cego, o surdo ou usuário de cadeira de rodas. Todas as crianças são crianças e têm o direito de serem vistas e tratadas como tais.

\title{
b) Barreira atitudinal de adjetivação ou rotulação
}

Tavares (2012) afirma que:

\begin{abstract}
A barreira atitudinal de adjetivação é o uso de rótulos ou atributos depreciativos em função da deficiência. Assim como a barreira atitudinal de substantivação, a de adjetivação também predispõe as pessoas sem deficiência a pressupor comportamentos da pessoa que foi rotulada compatíveis com a representação social que foi imposta a ela (TAVARES, 2012 p. 125).
\end{abstract}

Diferentemente da substantivação, a barreira atitudinal de adjetivação desqualifica o sujeito por sua deficiência. O indivíduo é considerado diferente da compreensão de normalidade culturalmente construída.

A barreira atitudinal da substantivação acaba apresentando no indivíduo estigmatizado o sentimento de insegurança em relação à maneira como os sujeitos culturalmente concebidos pela ideologia da normalidade o identificam e o recebem (GOFFMAN, 2004). O ato de rotular algo desconhecido é o recurso pelo qual um determinado grupo, na maioria das vezes, de forma preconceituosa, concebe o ser rotulado. Porém, o rótulo é limitado e, mais ainda, amordaça e classifica o ser rotulado como diferente ou anormal.

Os educadores, comprometidos com a inclusão escolar, têm a responsabilidade de romper com esta barreira e buscar no conhecimento os caminhos para empoderar seu aluno no processo de ensino e aprendizagem. O conhecimento íntimo só se torna possível quando o educador coloca-se de forma elementar em relação com o outro, portanto, quando ele se torna presença para si. É nessa relação de ver o aluno sujeito aprendiz como sujeito de conhecimento que rompemos rótulos e vemos a criança que deseja aprender (BUBER, 2009). 


\title{
c) Barreira atitudinal de rejeição
}

\begin{abstract}
A barreira atitudinal de rejeição é a recusa irracional de interagir com uma pessoa em razão da deficiência. Essa recusa se faz não por medo, nem por ignorar como agir perante uma pessoa com deficiência. A rejeição não se deve a uma experiência anterior com o indivíduo ou grupo a partir do qual se generaliza uma experiência ruim, ela é a mera expressão da recusa por razão de deficiência, independentemente de quaisquer atributos "positivos" relacionados a uma pessoa ou grupo (TAVARES 2012, p. 131).
\end{abstract}

Tavares (2012) e Goffman (2004) apontam que as relações entre os sujeitos culturalmente compreendidos como normais e estigmatizados se apresentam de forma desconfortável para ambos. Primeiramente, porque os sujeitos concebidos na cultura normalista não conseguem enxergar os sujeitos estigmatizados como igualmente normais. Segundo, porque os estigmatizados tendem a sempre se colocar em posição de retaguarda.

Ampliando esse entendimento, Goffman (2004) ressalta que sujeitos excluídos tendem a ter as mesmas crenças sobre a identidade, semelhantes àquelas definidas "culturalmente como normais", pois estão inseridos na mesma cultura, muitas vezes, possuem os mesmos valores, passando a acreditar na definição de seus limites abaixo do que realmente são, consequência da interação com a sociedade em que vivem.

Como vimos, a inclusão é mais que apenas uma teoria ligada à educação; inclusão é estar aberto ao novo, buscar esse novo, reconhecer o diferente como nosso semelhante. A inclusão começa conosco, na nossa prática cotidiana, em nossa sala de aula e com nossos alunos.

A escola não foi pensada para atender a todos. Os cursos de formação partem do pressuposto de atender alunos que respondem culturalmente às propostas educacionais, sem se levar em conta a diversidade (BOURDIEU, 1998). Os alunos são pensados em modelos didáticos na perspectiva de pessoas sem deficiência.

Em decorrência disso, as pessoas com deficiências acabam sendo evidenciadas por estereótipos e rejeitadas por não serem acreditadas como sujeitos capazes de méritos sociais. Tendem a desenvolver estratégias para superar as barreiras impostas pelo ambiente social e provar que conseguem ir além, aproximando-se ao máximo do que consideram como a normalidade construída nos campos para se sentirem aceitas socialmente. 
Não podemos negar que a humanidade é plural, sendo assim, não existe mais lógica em se exigir uma sociedade homogênea, pregada dogmaticamente por séculos. Partir deste princípio e ter como horizonte o valor da vida, corroborada nos Direitos Humanos, sinaliza a urgência de garantir o acesso e a participação de todos a todas as possibilidades que compõem uma sociedade (SESCONETO; STIEGLER, 2007).

\section{CONSIDERAÇÕES FINAIS}

Apresentamos autores que dialogaram e classificaram questões sociais com a teoria da inclusão. Buscamos nessas categorias uma interlocução entre a escola regular e o sujeito com deficiência.

Nossa pesquisa permitiu abrir uma nova percepção referente aos aspectos sociais que promovem as barreiras atitudinais e excluem pessoas que estão fora do padrão que a educação está acostumada a atender. Não devemos esquecer de permanecer sempre atentos às sutilezas das barreiras atitudinais, pois, como vimos ao longo da discussão, a teoria da educação inclusiva esclarece que não podemos mais esperar para construir uma sociedade que respeite a diferença. Precisamos de ação. A sociedade contemporânea, excludente, precisa ser superada.

Contudo, as sociedades vêm atravessando diversas fases relativas às práticas educativas. De um momento histórico compreendido como exclusão total do indivíduo à educação, pois estes se enquadravam no padrão de normalidade instituído socialmente pela ideologia dominante, passando pelos movimentos de segregação escolar, em que escolas ou salas de aula eram especiais, até culminar com tentativas de inclusão educacional (SASSAKI, 1997).

O processo de inclusão na escola, embora tenha dado seus passos mais significativos no início dos anos 2000, ainda é uma faceta recente da nossa história da educação. Entendemos que, para que haja impactos nas estruturas das sociedades, a inclusão emerge como uma ferramenta contra as diferentes formas de barreiras, sejam elas arquitetônicas, comunicacionais ou atitudinais; vem contra o segregacionismo, como o representado pela educação especial; contra o racismo como sofrem os negros, muçulmanos, asiáticos e homossexuais; vem contra a negação do ser diferente (WERNEK, 1999). 


\section{REFERÊNCIAS BIBLIOGRÁFICAS}

ABBAGNANO, N. Dicionário de filosofia. 2.ed. - São Paulo: Martins Fontes, 1998.

ALVES-MAZZOTTI, A. J. O método nas Ciências Sociais. In: ALVES-MAZZOTTI, A. J.; GEWANDSZ NAJDER, F. O método nas ciências naturais e sociais: pesquisa quantitativa e qualitativa. São Paulo: Pioneira, 1999.

BAUER, M. W. / GASKELL, G. Pesquisa Qualitativa Com Texto, Imagem E Som. Ed. VOZES (2005)

BOURDIEU, P. Razões Práticas: Sobre a Teoria da Ação. Campinas SP. Papiros, 2011.

A economia das trocas simbólicas. São Paulo: Perspectiva, 2007.

Escritos de Educação. Petrópolis: Vozes, 1998.

O poder simbólico. Lisboa: Difel, 1989.

BURKE, P. (Org). A Escrita Da História, Novas eruptivas. Editora: UNESP $3{ }^{\text {a }}$ Edição - 2001.

BUBER, M. Eu e Tu. Editora: CENTAURO, $2^{\text {a }}$ Edição - 2009

CHIZZOTTI, A. Da pesquisa qualitativa, In: Pesquisas em ciências humanas e sociais. 2.ed. São Paulo: Cortez, 1997.

FELTRIN, A. E. Inclusão Social na escola: quando a pedagogia se encontra com a diferença. São Paulo, Editora Paulinas 2004.

GOFFMAN, E. Estigma - Notas Sobre A Manipulação Da Identidade Deteriorada 4 ed. 2004. Disponível em

$<$ http://disciplinas.stoa.usp.br/pluginfile.php/92113/mod_resource/content/1/Goffman\% 3B\%20Estigma.pdf>. Acesso em 20 abr. 2016.

Inclusão em educação: culturas, políticas e práticas / Mônica Pereira dos Santos, Marcos Moreira Paulino (orgs.). - São Paulo: Cortez, 2008.

HARARI, Y. N. Sapiens - uma breve história da humanidade. Editora L\&PM. Rio Grande do Sul, RS: 2015

LAPLANE, A. F. DOBRANSZKY, E A. Capital cultural: ensaios de análise inspirados nas idéias de P. Bourdieu. Horizontes, Bragança Paulista, v. 20, p. 59-68, jan./dez., 2002. Disponível em

$<$ https://bibliotecadafilo.files.wordpress.com/2013/10/21-laplane-a-dobranszky-ecapital-cultural-ensaios-de-anc3a1lise-inspirados-nas-idc3a9ias-de-p-bourdieu.pdf $>$. acesso em 10 abr. 2016.

LIMA. F. J. e SILVA, F. T. dos S. Barreiras Atitudinais: obstáculos à pessoa com deficiência na escola. Disponível em:

〈http://www.adiron.com.br/site/uploads/File/Barreiras\%20Atitudinais.pdf $>$. Acesso em 14 jun. 2009. 
MANTOAN, M. T. E. Inclusão escolar: o que é? Por quê? Como fazer? São Paulo: Moderna, 2003.

Inclusão escolar: pontos e contrapontos. Editora Summus, São Paulo, 2006.

MAZZOTTI, A. J.; GEWANDSZ N. A. F. O método nas ciências naturais e sociais: pesquisa quantitativa e qualitativa. São Paulo: Pioneira, 1999.

NOGUEIRA, C.M.M. Limites da explicação em sociologia da educação: considerações a partir de pesquisas sobre o processo de escolha do curso superior. In: SBS-XXII Congresso Brasileiro de Sociologia. Minas Gerais, 2006. GT

03 Educação e Sociedade. Disponível em:

$<$ http://www.sbsociologia.com.br/portal/index.php?option=com_docman\&task=doc_do wnload\&gid=1080\&Itemid=171>. Acesso em 20 mar. de 2016.

NOGUEIRA, M. A; NOGUEIRA, C. M. M. Bourdieu e a educação. 2. ed. São Paulo: Autêntica, 2006.

PERLIN E STROBEL. Fundamentos da Educação de Surdos. Disponível em: $\langle$ http://www.scribd.com/doc/4559884/Fundamentos-da-Educacao-dos-Surdos >. Acesso em 15 jan. 2010.

QUADROS, R. M. P., Gladis (org). Estudos surdos II / - Petrópolis, RJ: Arara Azul, 2007.

RIBEIRO, E. N. A imagem na relação de expressão com o texto escrito: contribuições da áudio-descrição para a aprendizagem de educandos surdos (PPGE/UFPE). - Recife: O autor, 2011.

SASSAKI, R. K. Inclusão! Construindo uma Sociedade para Todos. Rio de Janeiro: WVA, 1997.

SESCONETO, C. R. STIEGLER, V. Educação Inclusiva. Um olhar para o futuro. Vol. 3, n. 11. ICPG, 2007.

TAVARES, F. dos S. S. Educação não inclusiva: a trajetória das barreiras atitudinais nas dissertações de educação do programa de pós-graduação em educação (PPGE/UFPE) - Recife: O autor, 2012.

WERNECK, C. Quem Cabe No Seu Todos? Editora: WVA 1ª Edição - 1999.

Recebido em: 07/02/2017

Aceito em: 04/10/2017 